\section{Influence of Low Temperature before Flowering on the Occurrence of Unreduced Pollen in Japanese Persimmon (Diospyros kaki Thunb.)}

\author{
A. Yamada, R. Tao, ${ }^{1}$ and A. Sugiura \\ Laboratory of Pomology, Graduate School of Agriculture, Kyoto University, \\ Kyoto 606-8502, Japan
}

Additional index words. Diospyros kaki, ploidy breeding, giant pollen, hexaploid

\begin{abstract}
The efficacy of ploidy breeding using unreduced pollen in japanese persimmon (Diospyros kaki Thunb.) is not high because of the low frequency of unreduced pollen in most cultivars. This study was conducted in 2002 and 2003 to determine if the exposure to a low temperature before flowering could enhance the unreduced pollen formation in five cultivars of japanese persimmon including two cultivars that barely produce unreduced pollen under the field condition. The results showed that low-temperature treatment (4 ${ }^{\circ} \mathrm{C}$ for 48 hours) increased the occurrence of unreduced pollen at 15 to 17 and 17 to 18 days after the end of the low-temperature treatment in 2002 and 2003, respectively, in all five cultivars tested. Naturally occurring temperatures below $5{ }^{\circ} \mathrm{C}$ in the field also appeared to enhance the unreduced pollen formation in the cultivars that naturally produce unreduced pollen in the field.
\end{abstract}

Most plant genera contain species with different ploidy levels and ploidy can even vary within a species. Change of ploidy often brings about acquisition of some horticulturally beneficial traits such as seedlessness, large fruit, polyploid vigor and thicker branches with short internodes (Sanford, 1983). Manipulation of ploidy, therefore, has been considered to be one of the most effective breeding techniques.

Japanese persimmon (Diospyros kaki Thunb.) is a polyploid fruit tree species that has been cultivated for over ten centuries in Japan. Namikawa and Higashi (1928) first reported that japanese persimmon is a hexaploid $(2 n=6 x=90)$ plant. Later, Zhuang et al. (1990) found that a few seedless cultivars are nonaploid $(2 \mathrm{n}=9 \mathrm{x}=135)$ in contrast to the hexaploidy of most seeded cultivars. Since no dodecaploid persimmons have been found in nature, the nonaploid cultivars are considered to arise from spontaneous crossing between reduced (n) and unreduced (2n) gametes. In fact, Sugiura et al. (2000) demonstrated the occurrence of unreduced giant pollen grains in several monoecious japanese persimmon cultivars and artificially produced nonaploid seedlings by crossing sorted giant pollen grains with a hexaploid female cultivar. Although this technique seems to be very promising for breeding nonaploid seedless cultivars of japanese persimmon, the efficacy of obtaining nonaploid plants was very low, and only about $3 \%$ of the seeds obtained had embryos that could be rescued by in vitro culture.

Received for publication 11 June 2004. Accepted for publication 8 July 2004. This work was supported in part by Wakayama Prefecture Collaboration of Regional Entities for the Advancement of Technological Excellence, Japan Science and Technology Agency. ${ }^{1}$ To whom reprint requests should be addressed; e-mail rtao@kais.kyoto-u.ac.jp.
Furthermore, the low incidence of giant pollen makes it difficult to use this technique in breeding programs.

Both genetic and environmental factors affect unreduced pollen formation. Specific genotypes produce a larger number of unreduced pollen grains in several plant species such as lily (Lilium spp.; van Tuyl and Stekelenburg, 1988), alfalfa (Medicago sativa; Calderini and Mariani, 1997), Lotus tenuis (Negri and Lemmi, 1998), and genus Vaccinium (Lyrene et al, 2003). A low or high temperature may stimulate the production of unreduced gametes. A low temperature stimulated the formation of unreduced pollen in Mexican lime (Citrus aurantifolia; Iwamasa and Iwasaki, 1963), mulberry (Morus spp.; Seki, 1956), and Dasypyrum villosum (Stefani and colonna, 1996). By contrast, a high temperature increased the frequency of unreduced pollen formation in perennial ryegrass (Lolium perenne; Den Nijis and Stephenson, 1988), Lotus tenuis (Negri and Lemmi, 1998), and lily (van Tuyl and Stekelenburg, 1988).

If the percentage of unreduced pollen formation could be increased by changing environmental factors before flowering, unreduced pollen could be more efficiently used for ploidy manipulation in japanese persimmon. As the first step towards this goal, this study was

Table 1. Number of trees of the five persimmon cultivars used in experiments in 2002-03.

\begin{tabular}{|c|c|c|c|c|c|}
\hline \multirow[b]{3}{*}{ Cultivar } & \multicolumn{5}{|c|}{ Trees used (no.) } \\
\hline & \multicolumn{2}{|c|}{2002 Expt. } & \multicolumn{3}{|c|}{2003 Expt. } \\
\hline & $\begin{array}{c}\text { Control } \\
\text { (field grown) }\end{array}$ & $\begin{array}{c}\text { Low-temp } \\
\text { treatment } \\
\text { (30 Apr.-2 May) }\end{array}$ & $\begin{array}{c}\text { Control } \\
\text { (field grown) }\end{array}$ & $\begin{array}{c}\text { Low-temp } \\
\text { treatment } \\
\text { (6-8 May) }\end{array}$ & $\begin{array}{c}\text { Glasshouse } \\
\text { treatment } \\
\text { (21 Apr.) }\end{array}$ \\
\hline Amayotsumizo & 4 & 4 & 10 & 4 & 4 \\
\hline Gosho & 20 & 0 & 16 & 4 & 0 \\
\hline Kakiyamagaki & 5 & 5 & 14 & 0 & 5 \\
\hline Okugosho & 4 & 3 & 16 & 0 & 3 \\
\hline Zenjmaru & 20 & 0 & 16 & 4 & 0 \\
\hline
\end{tabular}

conducted to determine if a low temperature before flowering could increase the formation of unreduced pollen in several cultivars of japanese persimmon.

\section{Materials and Methods}

Plant materials. Five monoecious japanese persimmon cultivars ('Amayotsumizo', 'Gosho', 'Kakiyamagaki', 'Okugosho', and 'Zenjimaru') were used in this study. Fouryear-old trees grafted on seedling rootstocks were grown in plastic pots $(25 \mathrm{~L})$ in the field at the experimental farm of Kyoto University, Kyoto. Previous studies showed that proportions of unreduced pollen grains in the pollen samples of 'Amayotsumizo', 'Gosho', and 'Zenjimaru' were about $5 \%$ to $18 \%$ but 'Kakiyamagaki' and 'Okugosho' barely produced unreduced pollen (Sugiura et al., 2000; Sugiura et al., unpublished data).

Low-temperature and glasshouse treatments. In 2002, several trees of 'Amayotsumizo', 'Kakiyamagaki', and 'Okugosho', and in 2003, several trees of 'Amayotsumizo', 'Gosho', and 'Zenjimaru' selected at random, were transferred to a cold room $\left(4{ }^{\circ} \mathrm{C}\right.$, dark; low-temperature treatment) about 1 week before the start of flowering (30 Apr. 2002 and 6 May 2003). These trees were returned to the field after a 48-h treatment. Although the first day of flowering varied slightly with the cultivars, we simultaneously started the low-temperature treatment. Since the flowering period lasted about 2 weeks, there should have been the flower buds at the same developmental stage regardless of the slight difference in the first day of flowering.

Several trees of 'Amayotsumizo', 'Kakiyamagaki', and 'Okugosho' were transferred to a glasshouse on 21 Apr. 2003, to protect them from naturally occurring low temperatures and grown there until the end of experiment (glasshouse treatment). In the glasshouse, the heater was adjusted to operate when the air temperature dropped to $8^{\circ} \mathrm{C}$. This setting kept the lowest air temperature in the glasshouse above $8{ }^{\circ} \mathrm{C}$. Field and glasshouse temperature was recorded every $30 \mathrm{~min}$ from $1 \mathrm{month}$ before flowering to the end of flowering.

The field grown potted trees (nontreated) were used as controls of the above two treatments. Table 1 shows the number of trees used for each treatment.

Determination of the percentage of unreduced pollen grains. During the 2 to 3 weeks of flowering period (under the experimental and field conditions), every male flower was observed daily and sampled when first opened. 
Flowers taken from different trees of the same treatment were pooled. After removing the sepals and petals, flowers were dried for $2 \mathrm{~d}$ at room temperature. Released pollen grains were pooled and placed in sealed glass vials, which were then stored at $-20^{\circ} \mathrm{C}$ with a silica gel desiccant until used. Aliquots of stored pollen were hydrated in cell and protoplast washing (CPW) solution with $0.9 \mathrm{M}$ mannitol (Draper et al., 1988) for $2 \mathrm{~h}$ with agitation. Micrographs of pollen grains were captured under a fluorescent microscope with UV excitation (main wave length at $365 \mathrm{~nm}$ ) and the area of each pollen grain in orthogonal projection was measured using a Scion Image software (Scion Co., Maryland). A histogram was drawn and the boundary between normal and unreduced giant pollens was determined. Because the diameter of unreduced giant pollen grain is about 1.3 times larger than that of reduced normal pollen grains (Sugiura et al., 2000; Zhuang, 1990), there are two peaks of reduced and unreduced pollen grains in the histogram if unreduced pollen grains are included in the sample. We determined the boundary between the two peaks visually considering both the histogram shape and the about 1.3 times larger diameter of unreduced pollen grains. We regarded the pollen grains larger than the boundary as unreduced pollen grains. More than 1000 pollen grains were measured per treatment. Because sample pollen grains were selected by random sampling and the populations were large enough, we calculated $95 \%$ confidence interval for unreduced pollen ratio of each population with binomial distribution (Freund, 1952).

\section{Results}

Experiment in 2002. Control trees of the persimmon cultivars started to flower at the beginning of May (Fig. 1) and flowering ended at around the end of May. Control trees of 'Amayotsumizo' started to flower on May 6, but those subjected to the low-temperature treatment (30 Apr. to 2 May) started to flower $2 \mathrm{~d}$ later, on 8 May (Figs. 1 and 2). Similarly, the flowering was delayed 2 and $3 \mathrm{~d}$ in ' $\mathrm{Ka}$ kiyamagaki' and 'Okugosho' trees subjected to low-temperature treatment, respectively (Figs. 1 and 2).

Figures 1 and 2 show the percentages of unreduced pollen grains in the control and low-temperature-treated trees, respectively, in 2002. Both control and low-temperaturetreated trees of 'Amayotsumizo' produced a large number of unreduced pollen grains (10\% to $23 \%$ ) within the first few days of flowering, namely on 6 to 9 May and 8 to 10 May, respectively. The second peak of production of unreduced pollen grains was observed at 6 to 7 $\mathrm{d}$ after the start of flowering in both control and low-temperature-treated trees, namely on 12 to 13 May in control trees and on 14 to 15 May in the low-temperature-treated trees (Figs. 1 and 2 ). The third peak of production of unreduced pollen grains was observed 9 to $11 \mathrm{~d}$ after the start of flowering, namely on 17 to 19 May, in the trees subjected to the low-temperature treatment (Fig. 2), but the third peak was not observed in the control trees (Fig. 1).

Control trees of 'Kakiyamagaki' and 'Okugosho' barely produced unreduced pollen grains throughout the flowering period (Fig. 1). However, when subjected to the low-temperature treatment, they produced some unreduced pollen grains ( $1 \%$ to $4 \%$ ) showing a peak on 18 and 17 May, respectively (Fig. 2).
Control trees of 'Zenjimaru' produced a large number of unreduced pollen ( $4 \%$ to $6 \%$ ) on 12 to 14 May, while those of 'Gosho' produced $2 \%$ to $3 \%$ of unreduced pollen during the first half of the flowering period.

Experiment in 2003. Control trees of 'Amayotsumizo' started to flower on 13 May, but the trees subjected to the low-temperature
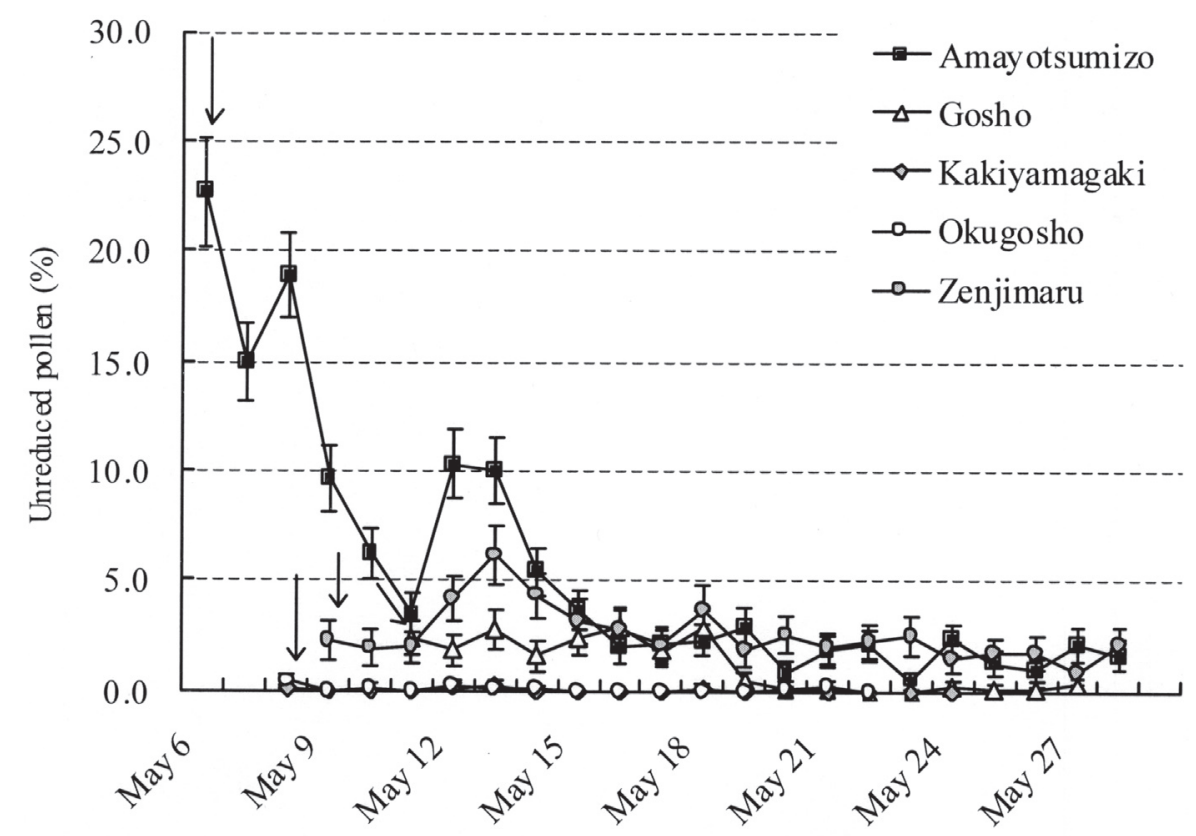

Flowering date

Fig. 1. Percentages of unreduced pollen grains in the pollen samples obtained from trees grown in the field (control) in 2002. Vertical bars represent $95 \%$ confidence intervals of unreduced pollen ratios of populations. Downward arrow = start of flowering.

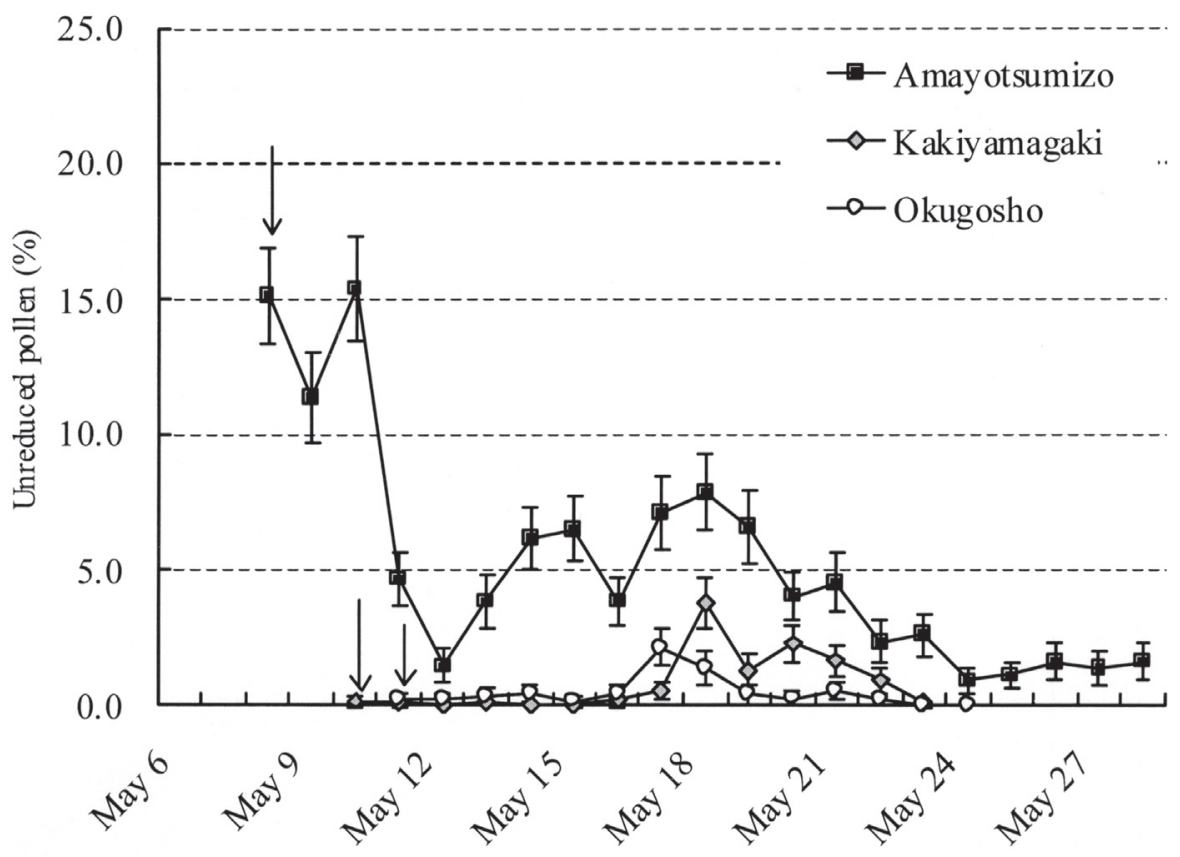

Flowering date

Fig. 2. Percentages of unreduced pollen grains in the trees subjected to the low-temperature treatment on 30 Apr. to 2 May 2002. Vertical bars represent $95 \%$ confidence intervals of unreduced pollen ratios of populations. Downward arrow = start of flowering. 
treatment (6 to 8 May) started to flower 2 d later, on 15 May (Figs. 3 and 4). The trees of 'Gosho' and 'Zenjimaru' in the control group started to flower on 18 and 15 May, respectively, but ment started to flower on 19 May, 1 and 4 d later as compared to the control trees, respectively. On the other hand, the trees of 'Amayotsumizo', 'Kakiyamagaki', and 'Okugosho' grown in the glasshouse started to flower on 8,10 , those subjected to the low-temperature treat-

and 9 May, respectively, 4 to $5 \mathrm{~d}$ earlier than the control trees which started to flower on 13 and 14 May (Figs. 3 and 5).

The percentages of unreduced pollen grains in 'Amayotsumizo', 'Gosho', and 'Zenjimaru' trees in the field (control) and those subjected to the low-temperature treatment were high ( $3 \%$ to $20 \%$ ) in the first few days of the flowering period irrespective of the treatment (Figs. 3 and 4). In control trees of 'Amayotsumizo' and

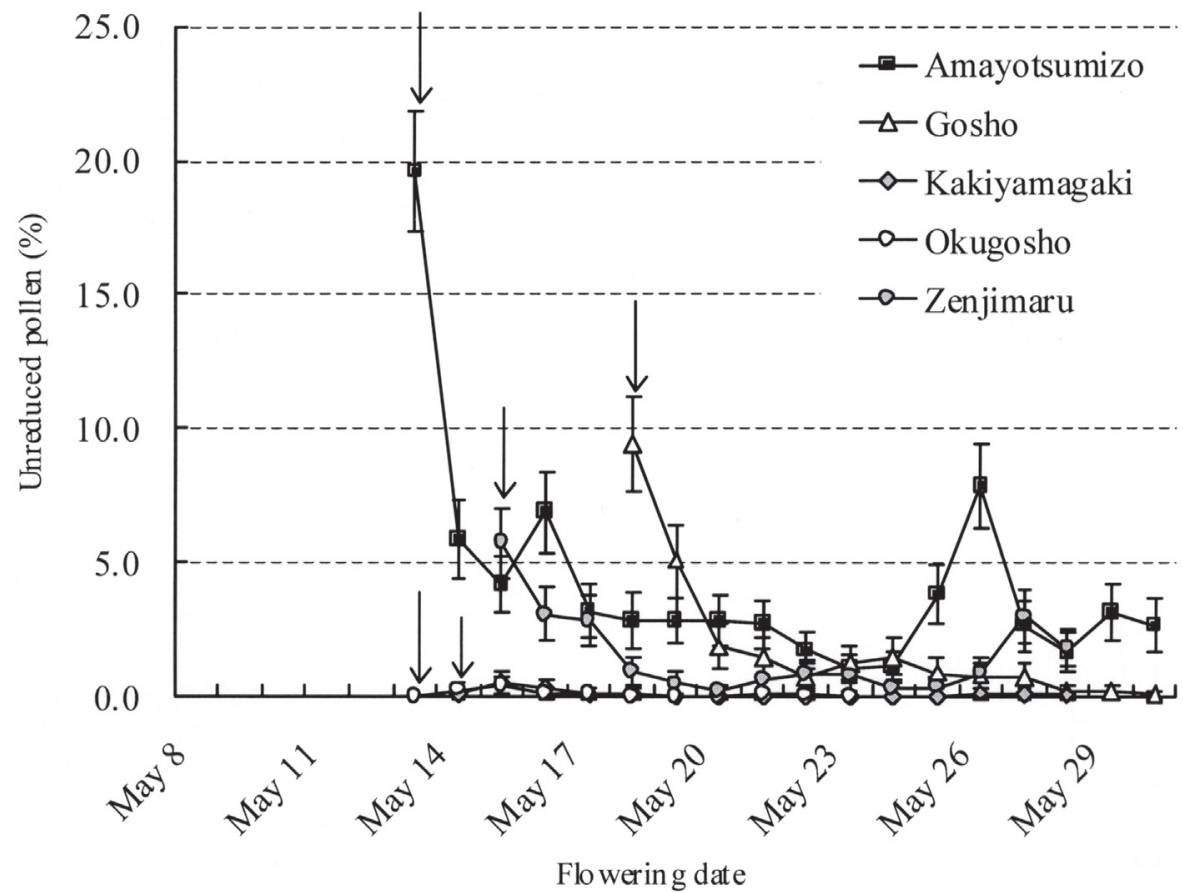

Fig. 3. Percentages of unreduced pollen grains in the pollen samples obtained from trees grown in the field (control) in 2003. Vertical bars represent 95\% confidence intervals of unreduced pollen ratios of populations. Downward arrow $=$ start of flowering.
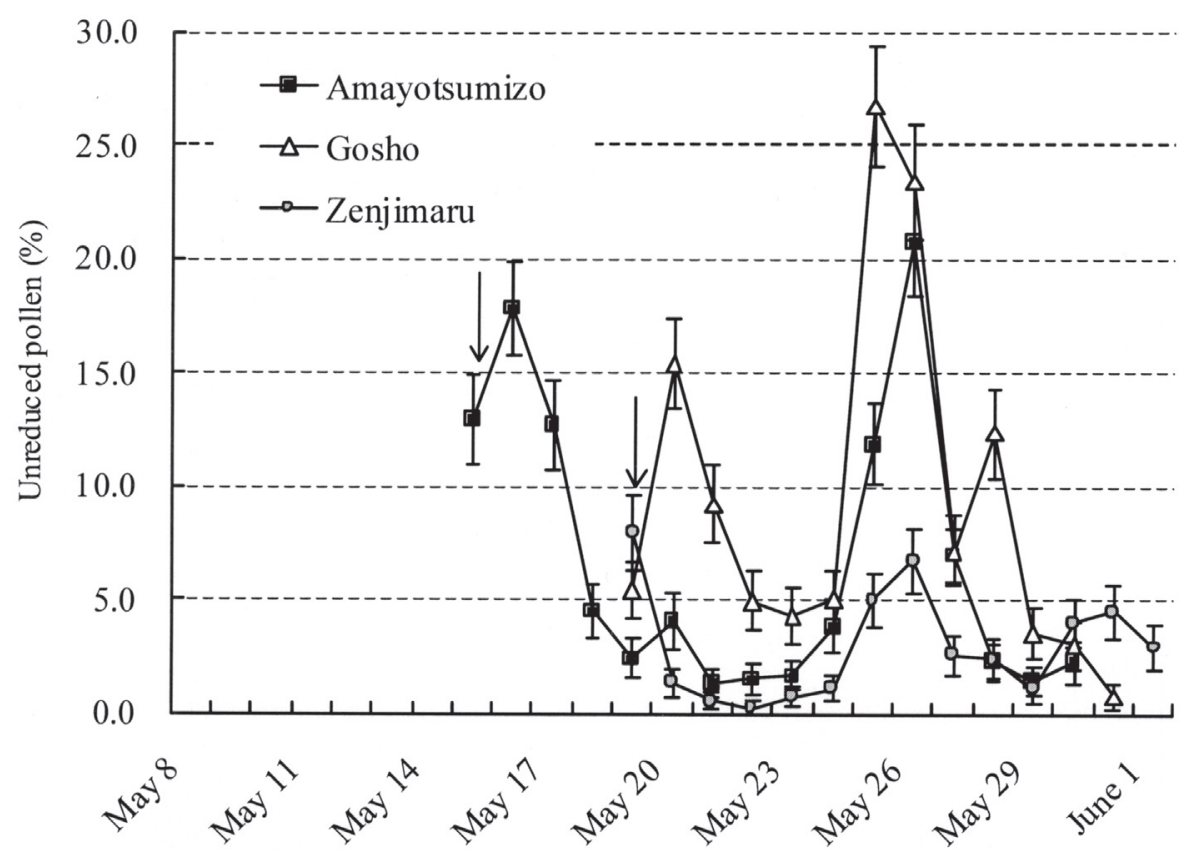

Flowering date

Fig. 4. Percentages of unreduced pollen grains in the trees subjected to the low-temperature treatment on 6 to 8 May 2003. Vertical bars represent $95 \%$ confidence intervals of unreduced pollen ratios of populations. Downward arrow $=$ start of flowering.
'Zenjimaru', the second peak of production of unreduced pollen grains observed on 25 to 26 May (4\% to $8 \%$ ) and on 27 to 28 May (2\% to $3 \%$ ), respectively (Fig. 3). In 'Amayotsumizo', 'Gosho', and 'Zenjimaru' trees subjected to the low-temperature treatment, the percentage of unreduced pollen grains changed with time (Fig. 4). Mode of the change varied with the cultivar, but the peak of the percentage of unreduced pollen grains was observed on 25 to 26 May (17 to $18 \mathrm{~d}$ after the end of the lowtemperature treatment) in all cultivars.

'Kakiyamagaki' and 'Okugosho' trees kept in the glasshouse barely produced unreduced pollen grains throughout the flowering period as in the control trees in the field (Figs. 3 and 5). 'Amayotsumizo' trees in the glasshouse, however, produced $5 \%$ to $10 \%$ of unreduced pollen grains during the first $3 \mathrm{~d}$ of flowering and a low percentage of unreduced pollen grains thereafter (Fig. 5).

\section{Discussion}

Flowering of the trees treated by low temperature delayed 1 to $4 \mathrm{~d}$ as compared to control trees in both years (Figs. 1-4). On the other hand, glasshouse grown trees flowered earlier than control trees by 4 to $5 \mathrm{~d}$ in 2003 (Figs. 3 and 5). Low-temperature treatment might have arrested the flower bud development while milder air temperature of glasshouse (Fig. 7) might have accelerated it. Therefore, we had to consider altered flowering period by temperature treatments to determine the effects on unreduced pollen formation. When percentages of unreduced pollen grains in control trees and low-temperature-treated trees of 'Amayotsumizo' in 2002 were compared, they were high (6\% to $23 \%$ ) for the first few days of flowering and 6 to $7 \mathrm{~d}$ after the start of flowering (Figs. 1 and 2); however, the third peak of production of unreduced pollen grains (7\% to $8 \%$ ) was observed on 17 to 19 May only in the trees subjected to low-temperature treatment. 'Kakiyamagaki' and 'Okugosho' trees subjected to low temperature treatment also produced unreduced pollen ( $1 \%$ to $4 \%$ ) on 17 to 21 May, while control trees barely produced unreduced pollen throughout the flowering period (Figs. 1 and 2). Namely, trees of all three cultivars subjected to low-temperature treatment produced higher percentage of unreduced pollen grains during the same period of 17 to 19 May ( 15 to $17 \mathrm{~d}$ after the end of the low-temperature treatment). These results suggest that the formation of unreduced pollen observed 15 to $17 \mathrm{~d}$ after the end of the lowtemperature treatment in these cultivars was induced by the low-temperature treatment. In 2003 , percentages of unreduced pollen grains in trees subjected to low-temperature treatment increased (5\% to $27 \%$ ) on 25 to 26 May in all three cultivars (Fig. 4). Low temperature treatment seemed to enhance the formation of unreduced pollen on 25 to 26 May (17 to $18 \mathrm{~d}$ after the end of the treatment) in 2003. The results are roughly consistent with those in 2002. These results could strongly suggest that low-temperature treatment before flowering enhanced the unreduced pollen formation 
in japanese persimmon. The small difference between the results obtained in 2002 and 2003 may be attributed to the difference in the natural temperature during the experimental period (Figs. 6 and 7).

To examine the effect of naturally occurring low temperatures on the formation of unreduced pollen in the control trees of 'Amayotsumizo', 'Gosho', and 'Zenjimaru', we investigated daily lowest air temperatures in the field (Figs. 6 and 7). The lowest temperature was below $5^{\circ} \mathrm{C}$ on 10 to 14,19 , and 26 to 27 Apr. 2002 (Fig. 6). Although the effect of the low temperature in the former two periods was unclear, the low temperature on 26 to $27 \mathrm{Apr}$. seemed to stimulate an increased formation of unreduced pollen grains in 'Amayotsumizo' and 'Zenjimaru', which was observed on 12 to 14 May 2002 ( 15 to $18 \mathrm{~d}$ after they were exposed to the low temperature). This conclusion was drawn based on the observation that unreduced pollen formation was increased 15 to $17 \mathrm{~d}$ after the end of the low-temperature treatment as mentioned above. Since the time of flowering was delayed 2 to $3 \mathrm{~d}$ by the lowtemperature treatment, the increased unreduced pollen formation observed on 14 to 15 May (18 to $19 \mathrm{~d}$ after $26 \mathrm{Apr}$.) in 'Amayotsumizo' subjected to the low-temperature treatment might also be induced by natural low tem-

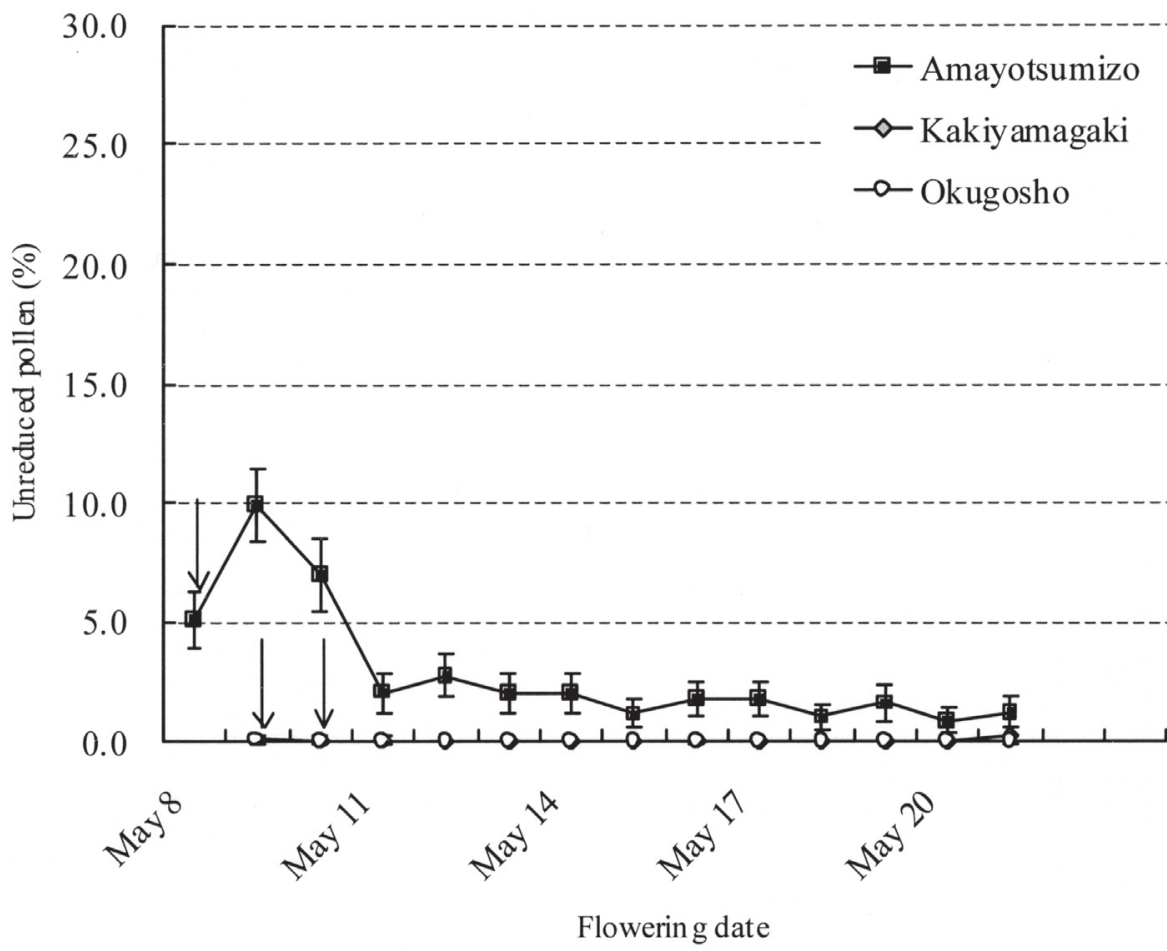

Fig. 5. Percentages of unreduced pollen grains in the trees grown in the glasshouse from 21 Apr. to the end of flowering in 2003. Vertical bars represent $95 \%$ confidence intervals of unreduced pollen ratios of populations. Downward arrow $=$ start of flowering.

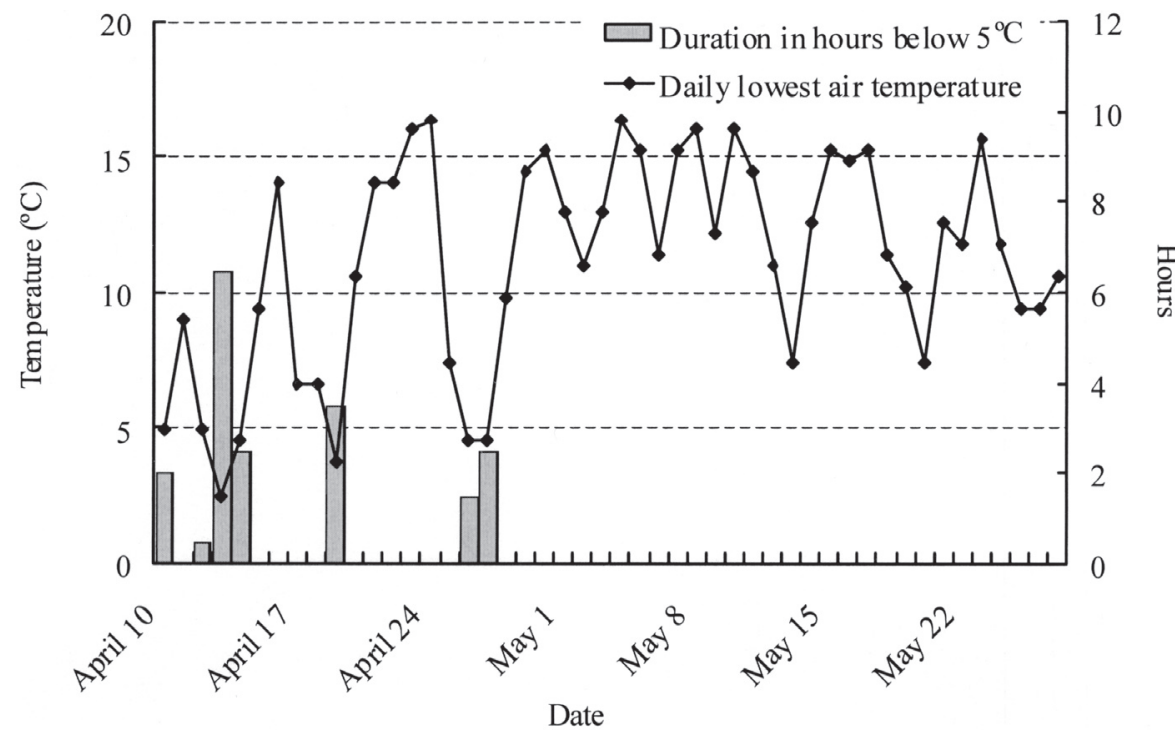

Fig. 6. The daily lowest air temperature and duration in hours below $5{ }^{\circ} \mathrm{C}$ in the field in 2002 . peratures on 26 to 27 Apr. (Fig. 2). In 2003, a temperature below $5{ }^{\circ} \mathrm{C}$ was recorded several times in the field (Fig. 7). Among them, the low temperature on 9 May seemed to enhance the occurrence of unreduced pollen in control trees of 'Amayotsumizo' on 25 to 26 May and in 'Zenjimaru' on 27 to 28 May (Fig. 3). These periods were 16 to 17 and 18 to $19 \mathrm{~d}$ after the control trees of 'Amayotsumizo' and 'Zenjimaru', respectively, encountered the natural low temperature on 9 May and well coincided with the results obtained from the low-temperature treatment.

It is noteworthy that the low-temperature treatment stimulated the formation of unreduced pollen not only in the cultivars naturally producing unreduced pollen ('Amayotsumizo', 'Gosho', and 'Zenjimaru') but also in the cultivars barely producing unreduced pollen in the field condition ('Kakiyamagaki' and 'Okugosho'). Although the occurrence of unreduced pollen was synchronously observed 15 to 17 and 17 to $18 \mathrm{~d}$ after the low-temperature treatment in 2002 and 2003, respectively, in all the cultivars tested, the sensitivity to the low temperature seemed to vary with the cultivar. The percentage of unreduced pollen grains produced by the low-temperature treatment was high in 'Amayotsumizo' than in 'Kakiyamagaki' and 'Okugosho' in 2002 (Fig. 2) and in 'Amayotsumizo' and 'Gosho' than in 'Zenjimaru' in 2003 (Fig. 4). The effect of naturally occurring low temperatures on the unreduced pollen formation also varied with the cultivars (Figs. 1 and 3). Occurrence of unreduced pollen was enhanced by the natural temperature below $5{ }^{\circ} \mathrm{C}$ that lasted only for a few hours in 'Amayotsumizo' and 'Zenjimaru', but such an enhanced unreduced pollen formation was not observed in 'Kakiyamagaki' and 'Okugosho'. The different levels of unreduced pollen formation observed among japanese persimmon cultivars (Sugiura et al., 2000) might be attributed to the different sensitivity to low temperature.

The occurrence of unreduced pollen tended to be high at the beginning of the flowering period even though the cultivars tested started to flower on different dates. In 2002, the highest percentage of unreduced pollen grain was recorded at the beginning of flowering both in the control and the low-temperature-treated trees of 'Amayotsumizo' (Figs. 1 and 2). In 2003 also, 'Amayotsumizo', 'Gosho', and 'Zenjimaru' trees produced a large number of unreduced pollen grains at the beginning of the flowering season (Figs. 3, 4, and 5). This could be caused by the early blooming flowers experiencing more low temperatures. Another possibility is that meiosis in pollen mother cells was unstable in the early flowers, and this led to an increased number of unreduced pollen grains. However, we excluded this possibility because the early blooming flowers of 'Kakiyamagaki' and 'Okugosho' barely produced unreduced pollen. There were no peaks of production of unreduced pollen grains at the first few days of flowering period in 'Gosho' and 'Zenjimaru' in 2002 (Fig. 1). This may be explained by the milder air temperature in 2002 than in 2003. The milder temperature in 2002 might also 


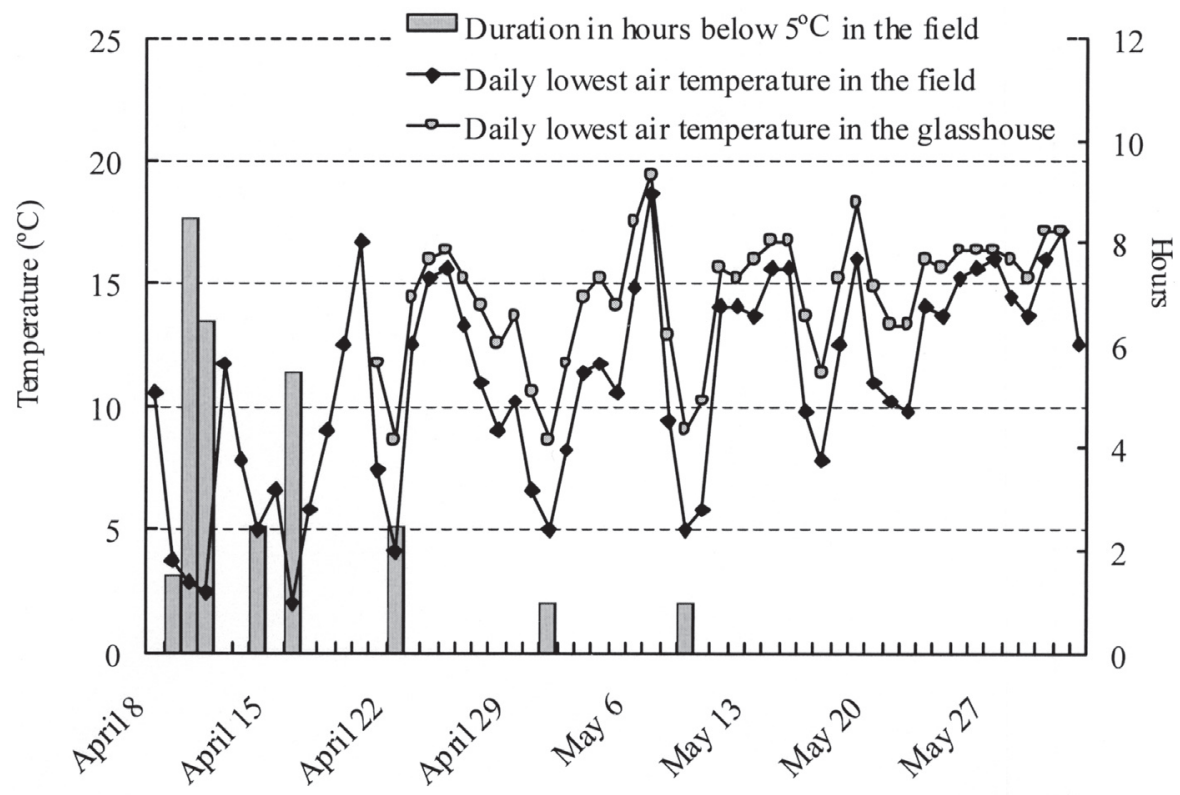

Date

Fig. 7. The daily lowest air temperature in the field and the glasshouse and the duration in hours below 5 ${ }^{\circ} \mathrm{C}$ in the field in 2003.

stimulate flower development, which lead to the earlier flowering in 2002. Compare to the control and low-temperature-treated trees, glasshouse grown 'Amayotsumizo' trees also produced less amount of unreduced pollen during the initial period of flowering (Figs. 3, 4 , and 5) and this is probably due to the milder air temperature in the glasshouse (Fig. 7).

In conclusion, the present study demonstrates the enhancement of unreduced pollen formation by low temperature and potential use of low-temperature treatment to enhance unreduced pollen formation in japanese persimmon. It is noteworthy that unreduced pollen formation of the cultivars that barely produce unreduced pollen in the field condition could be enhanced by the treatment.

\section{Literature Cited}

Calderini, O. and A. Mariani. 1997. Increasing of 2n gamete production in diploid alfalfa by cycles of phenotypic recurrent selection. Euphytica 93:113-118.

Den Nijis, A.P.M. and A.G. Stephenson. 1988. Potential of unreduced pollen for breeding tetraploid perennial ryegrass, p. 131-136. In: P. Gori and E. Pacini (eds.). Sexual reproduction of higher plants. Springer Verlag, Berlin.

Draper, J., R. Scott, P. Armitage, and R. Walden. 1988. Plant genetic transformation and gene expression. Blackwell Sci. Publ., Oxford, U.K.

Freund, J.E. 1952. Modern elementary statistics. Prentice-Hall, Inc., Englewood Cliffs, N.J.

Iwamasa, M. and T. Iwasaki. 1963. On the sterility phenomenon caused by low temperatures in the Mexican lime (Citrus aurantifolia Swingle) (in Japanese with English summary). Bul. Hort. Res. Sta., Japan. Series B, No. 2:25-41.

Lyrene, P.M., N. Vorsa, and J.R. Ballington. 2003.
Polyploidy and sexual polyploidization in the genus Vaccinium. Euphytica 133:27-36.

Namikawa, I. and M. Higashi. 1928. On the number of chromosomes in D. kaki Linn. and D. lotus Linn. Bot. Mag. 42:436-438.

Negri, V. and G. Lemmi. 1998. Effect of selection and temperature stress on the production of 2n gametes in Lotus tenuis. Plant Breeding 117:345-349.

Sanford, J.C. 1983. Ploidy manipulations, p. 100-123. In: J.N. Moore and J. Janick (eds.). Methods in fruit breeding. Purdue Univ. Press, W. Lafayette, Ind.

Seki, H. 1956. Cytological studies of mulberry pollen mother cells subjected to low temperature (in Japanese with English summary). Res. Rpt. Fac. Textile and Sericult., Shinshu Univ. 20:1-59.

Stefani, A. and N. Colonna. 1996. The influence of temperature on meiosis and microspores development in Dasypyrum villosum (L.) P. Candargy. Cytologia 61:277-283.

Sugiura, A., T. Ohkuma, Y.A Choi, R. Tao, and M. Tamura. 2000. Production of nonaploid $(2 \mathrm{n}=$ 9x) japanese persimmons (Diospyros kaki) by pollination with unreduced $(2 n=6 x)$ pollen and embryo rescue culture. J. Amer. Soc. Hort. Sci. 125:609-614.

van Tuyl, J.M. and P.B. Stekelenburg. 1988. Genotypic and environmental variation in production of 2n-gametes in Lilium, p. 486. In: P. Gori and E. Pacini (eds.). Sexual reproduction of higher plant. Springer Verlag, Berlin.

Zhuang, D. 1990. Cytogenetic studies on japanese persimmon cultivars-On the chromosome number of seedless cultivars (in Japanese with English summary). PhD diss. Kyoto Pref. Univ., Kyoto, Japan.

Zhuang, D., A. Kitajima, M. Ishida, and Y. Sobajima. 1990. Chromosome number of Diospyros kaki cultivars (in Japanese with English summary). J. Jpn. Soc. Hort. Sci. 59:289-297. 